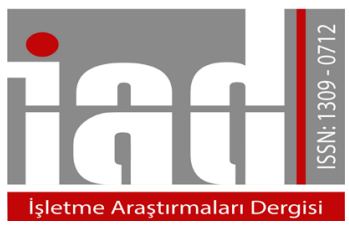

\author{
İşletme Araştırmaları Dergisi \\ Journal of Business Research-Turk \\ 10/4 (2018) 820-842
}

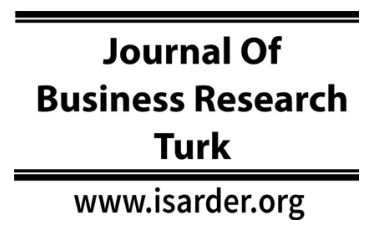

Araștırma Makalesi

\title{
Bütünleşik Dematel ve GİA Yöntemleri İle Seyahat Acentalarında Lojistik Performans Unsurlarının Ölçülmesi ve En İdeal Seyahat Acentası Seçimi: Giresun İli Örneği
}

\author{
Measurement of Logistics Performance Elements in Travel Agencies with \\ Integrated Dematel and GIA Methods and Selection of The Most Ideal \\ Travel Agency: Case of Giresun Province
}

\author{
Selçuk KORUCUK \\ Giresun Üniversitesi \\ Uygulamalı Bilimler Yüksekokulu \\ Giresun, Türkiye \\ orcid.org/0000-0003-2471-1950 \\ selcuk.korucuk@giresun.edu.tr
}

\author{
Eray TURPCU \\ Giresun Üniversitesi \\ Uygulamalı Bilimler Yüksekokulu \\ Giresun, Türkiye \\ orcid.org/0000-0003-2732-6222 \\ eray.turpcu@giresun.edu.tr
}

\author{
Hakan AKYURT \\ Giresun Üniversitesi \\ Uygulamalı Bilimler Yüksekokulu \\ Giresun, Türkiye \\ orcid.org/0000-0002-6522-684X \\ hakan.akyurt@giresun.edu.tr
}

\section{Özet}

Seyahat acentalarında lojistik performans faktörlerinin değerlendirilmesi ve bu değerlendirmelere göre gerekli düzeltmelerin ve iyileştirmelerin yapılması önem arz eden bir konu olarak düşünülmektedir. $\mathrm{Bu}$ çalışmada, Giresun ili'ndeki seyahat acentalarında lojistik performans faktörleri değerlendirilmiş ve en ideal seyahat acentası seçimi yapılmıştır. $\mathrm{Bu}$ amaçla lojistik performans unsurlarının belirleyicisi olan kriterlerin ağırlıkları DEMATEL yöntemi ile tespit edilmiştir. Daha sonra, GİA yöntemiyle en ideal seyahat acentası seçimi yapılarak sıralanmıştır. Yapılan değerlendirme sonucunda, lojistik performans unsurlarından en önemlisinin "Seyahat Hizmet Kalitesi" olduğu, GİA (Gri İlişkisel Analiz) yöntemi ile elde edilen sonuçta ise en ideal seyahat acentasının "Firma D" olduğu saptanmıştır.

Anahtar Kelimeler: Lojistik Performans, Seyahat Acentası, DEMATEL, GİA.

Gönderme Tarihi 4 Haziran 2018; Revizyon Tarihi 5 Aralık 2018; Kabul Tarihi 10

Aralık 2018

Önerilen Atıf/ Suggested Citation:

Korucuk, S., Turpçu, E., Akyurt, H. (2018). Bütünleşik Dematel ve Gia Yöntemleri İle Seyahat Acentalarında Lojistik Performans Unsurlarının Ölçülmesi Ve En İdeal Seyahat Acentası Seçimi: Giresun İli Örneği, İşletme Araştırmaları Dergisi, 10 (4), 820-842. 


\begin{abstract}
Evaluation of logistics performance factors in travel agencies and making necessary corrections and improvements are considered to be an important issue. In this study, travel agencies logistics performance factors were evaluated in Giresun province and the most ideal travel agency was selected. For this purpose, the weights of the criteria which are the determinants of the logistic performance were determined by DEMATEL method. Then, the most appropriate travel agency was selected by the GRA method and sorted. As a result of the evaluation, it was found that "Travel Service Quality edil was the most important logistics factor and itesi Firm D lojistik was the most ideal travel agency obtained by GIA (Gray Relational Analysis) method.
\end{abstract}

Keywords: Logistics Performance, Travel Agency, DEMATEL, GIA.

Received 4 June 2018; Received in revised from 5 December 2018; Accepted 10 December 2018

\title{
GİRIŞ
}

Turizmde meydana gelen değişimler sonucunda, turistlerin tatil planlarını yaparken veya satın alma davranışı içerisine girdiklerinde, seyahat acentalarının önemli bir rol üstlendiği görülmektedir. Bunun nedeni; güven, bilgi edinme, zaman tasarrufu, kredi imkânları ve maliyetlerde indirim sağlanması gibi turistler için en önemli konuların çözülmesinde yardımcı olunmasındaki seyahat acentalarının rolüdür. Seyahat acentaları, turistlerin evlerinin önünden alınıp tatillerini geçirecekleri turizm noktalarına varıncaya kadar ki tüm işlemleri gerçekleştirebilmektedir. Bununla birlikte, ulusal ya da uluslararası alanda çalışan acentalar turistler için tatil rotaları düzenlemekte, tatillerini geçirdikleri yerlerde geziler, turlar düzenlemekte ve tatil süresi boyunca konukları ile ilgilenmektedirler. Bu şartların sağlanması, seyahat acentaları ile seyahat eden ve tatillerini geçiren turist sayısında çok ciddi artışlar yaşanmasını ve dolayısıyla seyahat acentası sayısının artmasını sağlamıştır.

Turistlerin seyahat acentası seçimi önemli bir kavram olarak karşımıza çıkmakla birlikte, seyahat acentalarının kendi özelliklerinin de etkili bir unsur olduğu gerçektir. Turistlerin acenta seçiminde seyahat acentalarının vermiş oldukları hizmetler ve acentaların özellikleri etkili olmaktadır. Birçok farklı hizmeti bir arada veren seyahat acentalarının temel işlevlerinden biri de taşımacılıktır. Seyahat acentaları insan taşımacılığında gerek turlar gerek transferler gerekse de bilet satışları ile taşımacılık işini yapmaktadırlar. $\mathrm{Bu}$ durum seyahat acentalarının lojistik kavramı ile ilişkili olduğunu ve temelde turizm sektöründe lojistik işlevini gerçekleştirdiğini göstermektedir. Lojistik, temel olarak askeri alanda araç-gereç ve birliklerin organizasyonunu tanımlamak için kullanılan bir kavram olsa da, bir plan veya operasyonun detaylı olarak örgütlenmesi ve uygulanmasını kapsamaktadır. Lojistiğin ana amacı, tüketicilere kısa sürede ulaşmak, en iyi kaynak kullanımını sağlamak ve diğer işletmeler karşısında rekabet üstünlüğü elde etmektir (Çanc1 ve Erdal 2003: 35). Turizmde lojistik özellikle kara, hava ve deniz yolu taşımacılığı ile ifade edilmektir. Bu taşımacılık sisteminde, insan taşımacılığı da turizm açısından lojistik sektörü içinde kabul edilmekte ve turizm sektöründe bu durumu özellikle seyahat acentaları aracılığ ile gerçekleştirmektedir.

$\mathrm{Bu}$ çalışma ile turizm sektöründe lojistik işlevini yürüten seyahat acentalarının lojistik performans unsurlarının belirlenmesi hedeflenmektedir. Belirlenen bu unsurlar 
ile seyahat acentalarının lojistik performansı ölçülerek, performans faktörlerinin önem dereceleri sıralanarak, en ideal seyahat acentası kriterleri ortaya konacaktır. Seyahat acentalarının performansının belirlenmesi için Çok Kriterli Karar Verme (ÇKKV) yöntemi olan Dematel ve Gri Sistem Teorisi kapsamında geliştirilen GİA yöntemleri kullanılmıştır. Çalışma sonuçlarında, Giresun'daki seyahat acentalarının lojistik performans unsurlarında kullanılacak kriterlerin değerlendirilmesi için çok kriterli karar modeli oluşturulmuştur. Giresun ili seyahat acentaları üzerinde yapılan araştırma ile seyahat acentalarının lojistik performansının durumu ortaya konmuştur. Elde edilen veriler 1şığında en uygun seyahat acentası seçiminde etkili unsurlar ortaya çıkarılmış ve Giresun ilinde faaliyet gösteren seyahat acentalarının sektörde daha iyi hizmet verebilmeleri için önerilerde bulunulmuştur.

\section{KAVRAMSAL ÇERÇEVE}

\section{Kavram Olarak Lojistik}

İşletme açısından lojistik, siparişlerin maliyetleri dikkat edilerek optimal şekilde sağlanması, günlük ve gelecekteki kârlılığı en üst seviyeye çıkaracak malzemenin, parçaların ve envanterin işletme içinde ve pazarlama kanallarında tedarik, taşınma ve depolanma süreçlerini stratejik olarak yönetilmesi olarak tanımlanmaktadır (Bowersox, 1997: 182). Dış ticaret açısından değerlendirildiğinde lojistik kavramı, "tüketicilerin belirli ücret karşılığında ihtiyaçlarını gidermek amaçlı olarak ürünlerin ihracatçı ülkeden ithalatçı ülkeye teslimini sağlayan faaliyetleri ve enformasyon unsurları" anlamına gelmektedir (Canitez ve Tümer, 2005: 153).

Gerçekleştirdiği işler bakımından tarihin ilk dönemlerine kadar uzayan bir geçmişi olan lojistik kavramı, literatürde 1960'lı y1llardan sonra görülmeye başlanmıştır. Ulaştırma sektöründeki maliyetlerin artması ile birlikte daha da önem kazanan bu kavram, işletmelerin ticari işlerinde kullanılmıştır. Daha az maliyetler ile lojistik faaliyetlerini gerçekleştirme çabasına yönelen işletmeler, taşıma, depolama ve dağıtımın işlevlerine özen göstermeye başlamıştır. Tüketicilerin istek ve ihtiyaçlarındaki değişiklikler ve teknolojik ilerlemeler ile birlikte lojistik faaliyet türleri de değişim göstermiştir. Sipariş ve dağıtım hizmetleri, ayrıştırma, proje taşımacılığı, üretim denetimi, geri dönüşüm, kalite kontrol, teknik destek, eğitim ve danışmanlık, pazar araştırması, marka desteği, satış ve tanıtım organizasyonu, araç temini, işyeri kiralama gibi uygulamalar lojistik kavramının içinde yer almaktadır (Bayraktutan ve Özbilgin, 2015: 96).

Özellikle lojistik maliyetlerinin artması ve işletmelerin maliyetleri düşürmek istemeleri nedeniyle, bu konuda çalışmalar yapılması zorunlu hale gelmiştir. İşletme lojistik maliyetleri genel olarak aşağıda belirtilen maliyetlerden oluşmaktadır (Lambert vd., 1998: 17):

- Taşıma maliyeti,

- Depolama maliyeti,

- Envanter maliyeti,

- Sipariş işleme maliyeti,

- Tedarik, elleçleme, dağıtım ve elden çıkarma giderleri,

- Müşteri hizmetleri giderleri.

Genel olarak işletmelerin özelliklerine ve çalışmakta oldukları sektörlere göre lojistik maliyetleri farklılıklar gösterebilmektedir. Ancak işletmeler açısından lojistik 
maliyetleri detaylı olarak ele alındığında, taşımacılık oranının $\% 45$, depolama oranının $\% 26$, sipariş işleme oranının $\% 20$ ve envanter maliyetleri oranının $\% 9$ olduğu ortaya çıkmaktadır (Bezirci ve Dündar, 2011: 298). Bu oranlar ele alındığında, maliyetlerin azaltılmasında lojistik faaliyetlerinin dikkatli ve sistemli bir şekilde yönetilmesi gerekmektedir. $\mathrm{Bu}$ nedenle son yıllarda işletmeler, lojistik faaliyetlerine özenle yaklaşmaktadır ve maliyetlerini azaltacak yöntemler bulmaya çalışmaktadır.

Lojistiğin uygulama alanının geniş olması ve maliyetlerinin işletmeler açısından önemli olması nedeniyle, dikkat edilmesi gereken bir konu haline gelmiştir. Konunun öneminden dolayı, işletme, mühendislik, muhasebe, insan kaynakları, pazarlama, yöneylem gibi çok farklı uzmanlık alanlarında çalışan araştırmacıların lojistik ile ilgili detaylı araştırmalar yapmasını sağlamıştır. Bu çalışmalarda, fiziksel dağıtım, iş lojistiği, malzeme yönetimi, satın alma ve tedarik, ürün akışı, pazarlama lojistiği, arz tedarik zinciri yönetimi gibi dağıtım ve lojistiği kapsayan kavramlar ortaya çıkmıştır (Rushton vd., 2000: 4).

\section{Lojistik Perfomans Ölçümü}

Lojistikte performans ölçümünün temel amacı, işletmenin amaçlarına ulaşmada uygulanan yöntemlerin etkinliğinin ve verimliliğinin ortaya çıkarılmasıdır. Kullanılan performans ölçüleri, uygun performans ölçüm sisteminin seçilmesini ve uygulanmasını ifade etmektedir. Performans ölçüm sistemi, verimlilik ve etkinlik hareketlerini ölçen bir metrikler bütünü olarak adlandırılabilir. Kısaca performans ölçüm sistemi, işletme amaçlarına ulaşmak ve işletme fonksiyonlarını geliştirmek, takip etmek ve yol göstermek için ortaya konulan işlemlerdir. Etkin bir şekilde yapılandırılmış ve şekillendirilmiş performans ölçüm sistemlerinin uygulanması ile taktiksel, stratejik ve operasyonel seviyelerde işletme amaçlarına ve hedeflerine ulaşmada etkin bir yönetim sistemi oluşacaktır. Lojistik faaliyetlerinin güvenli, hızlı ve uygun fiyatlı olması önem arz eder ve aynı zamanda kaliteli bir hizmet anlayışı içerisinde yürütülmesi gerekir. Çünkü, etkin ve hızlı lojistik hizmetleri, üreticilerin pazarlara hızlı girişine ve ürün maliyetlerini azaltmaya imkân verecektir.

Ülkelerin dış dünya ile ticaret yapmasını kolaylaştıran lojistik, işletmelere rekabet gücü de kazandırmaktadır (Bayraktutan ve Özbilgin, 2015: 98).

İşletme maliyetlerinin azaltılması ve verimliliklerinin üst düzeye çıkarılmasında yardımcı unsurlardan biri de lojistik performansıdır. Lojistik performansının belirlenmesinde işletme için en uygun performans ölçütlerinin seçilmesi ve uygulanması gerekir. Bu durum işletmenin amaçlarına ulaşmasında önem arz etmektedir. Performans ölçümünün doğru bir şekilde seçilmesi, uygulama ve değerlendirme aşamalarında işletmelere önemli avantajlar sağlayacaktır. Performans ölçütlerinin ana amacı, müşteri ihtiyaçlarını karşılamada işletmelerin ne derece başarılı olduğunu ölçmektedir. Ayrıca, yapılan ölçümlerle işletmenin ürün ve hammadde giriş-çıkışında da yardımcı olmaktadır (Landers vd., 2008: 4).

Literatürde yapılan çalışmalarda işletmelerin performanslarının ölçülmesinin önemi açık bir şekilde ifade edilmektedir. Lojistik performans ölçümleri ile ilgili çeşitli çalışmalar bulunmaktadır. Performans ölçümünde kullanılan yöntemlerden biri, çalışmada da uygulanılan Çok Kriterli Karar Verme (ÇKKV) yöntemidir. İşletmelerin performans ölçümlerinde birbiriyle çelişen subjektif ve objektif çok sayıda değerlendirme kriteri kullanılması nedeniyle özellikle son yıllarda ÇKKV tekniklerinin kullanıldığı çalışma sayısı artmıştır. ÇKKV yöntemleri çalışmayı yapan araştırmacıların 
yargılarını dikkate alması bakımından subjektif olarak görülmekle birlikte, matematiksel algoritma kullanması nedeniyle de objektif analiz yöntemleri olarak değerlendirilmektedir. İşletmelerin günümüzde çok fonksiyonlu olmasından dolayı işletmeler arasında performans kıyaslaması yapılmasında ÇKKV yöntemlerinin kullanılmasının uygulamada basit olacağı ve etkili sonuçlara ulaşılacağı düşünülmektedir (Çakır ve Perçin, 2013: 450).

\section{Seyahat Acentaları ve Lojistik}

Lojistik kavramı içerisinde turizm sektörüne pek değinilmemiş olsa da, turizm sektörü yapısı gereği lojistik faaliyetlerini iki yönlü olarak kullanmaktadır. Bir yönü ile turist istek ve ihtiyaçlarını karşılayacak ürün satın alımında lojistik önem arz etmektedir. Turist memnuniyeti açısından ürün ve hizmetlerin zamanında ihtiyaçlara cevap vermesi gerekmektedir. Diğer yönü ile lojistik hizmetleri kara, hava, demir ve deniz yolu ile yapılan faaliyetler olarak düşünüldügünde, turizm sektörünün özellikle yolcu taşımacılığında tüm bu ulaşım araçlarını kullandığı gerçeği göz ardı edilemez. Aracı kurum olan seyahat acentalarının turistlere sunduğu bu hizmetler lojistik kavramının konusu içinde yer almaktadır. Turizm sektöründe ürünlerin lojistiği kadar turistlerin lojistiği de önemli konulardan biridir.

Seyahat acentaları turistik mal ve hizmet satmak isteyen işletmelerin ürünlerini ve de hizmetlerini işletmeler adına komisyon karşılığında satmaya çalışan, turistlerin seyahatleri ile ilgili hizmetleri paketler dahilinde sunan, tur organizasyonları düzenleyen, turistlere bilgi veren, ulaşım koşulları sağlayan, araç kiralayan ve seyahat sigortası gibi hizmetleri sunan işletmelerdir (Çolakoğlu ve Çolakoğlu, 2007: 11). Globalleşen ve kendini sürekli yenilemek zorunda olan turizm sektöründe, seyahat acentaları birçok faaliyeti gerçekleştirmektedir. Tur düzenlemek, transfer hizmeti vermek, rezervasyon ve bilgilendirme yapmak, kongre ve konferans organizasyonları gerçekleştirmek, araç kiralamak, bilet satışı yapmak, otel tanıtımı yapmak gibi birçok farkl1 hizmeti turistlere sunmaktadır (Zengin, 2004: 51). Belirtilen bu hizmetlerin birçoğu da lojistik sektöründe gerçekleştirilmektedir. Bununla birlikte, seyahat acentaları milyonlarca turisti havayolu ve karayolu ile turistik destinasyonlara ulaştırma faaliyetlerini gerçekleştirmektedir. Birleşmiş Milletler Dünya Turizm Örgütünün (UNWTO) 2018 turizm raporunda, 2017 yılı içerisinde dünya genelinde turizme katılan turist sayısı 1,3 milyar kişi ve turizm geliri de 1,343 milyar dolar olarak belirtilmektedir (UNWTO, 2018). Dünya genelinde turizmin payı düşünüldüğünde, seyahat acentalarının bu sistem içerisinde önemli rol oynadığı söylenebilir. Turizm alanında lojistik faaliyetler yürütmede etkin görevi olan bu işletmelerin lojistik performans durumları da önem arz etmektedir.

Seyahat acentalarının rol aldığı lojistik faaliyetleri kara, hava ve deniz olmak üzere üç kısımda ele almak mümkündür. Bu faaliyetler içerisinde seyahat acentalarının rolü günümüzde giderek artmaktadır. Turistler satın alma davranışlarını güvendikleri seyahat acentaları ile yapmakta ve dolayısıyla seyahat acentaları lojistik faaliyetlerine doğrudan katılmaktadır. Deniz taşımacılığında turizm sektörü özellikle kruvaziyer gemiler ile bu faaliyetleri gerçekleştirmektedir. Kruvaziyer turizmi, ana amacı gemide olan yolcuların konaklaması ve daha önceden oluşturulmuş belirli rotalar ile turistik destinasyonlarda tatillerini geçirmek amacıyla deniz yolculuğu için bilet satın alınması olarak ifade edilmektedir (Wild ve Dearing, 2000: 319). Uluslararası Kruvaziyer Hatlar1 Birliği (CLIA) 2017 Kruvaziyer Sektörü raporuna göre, dünya kruvaziyer turizmi yolcu 
sayıs1 25,8 milyon kişidir (CLIA, 2018: 7). Bu durum deniz lojistiğinin turizm ve dünya pazarında ne kadar önemli olduğunu net bir şekilde göstermektedir.

Seyahat acentalarının lojistik işlevi, turistlerin ilk yola çıktıkları yerden başlayıp, tatilleri süresince ve tatillerinin bitimine yani geliş destinasyonlarına kadar sürebilmektedir. Turist isteklerine göre farklılık gösteren bu işlevler, seyahat acentalarının lojistik performanslarına göre değişebilmektedir. Seyahat acentalarının lojistik performanslarının niteliğinden işletmenin kendisinin etkilenebileceği gibi tatilini yapacak olan turistler ve konaklama tesisleri de olumlu ya da olumsuz olarak etkilenebilmektedir. İşletmelerin genel maliyetlerine ve turistlerin satın alma fiyatlarına doğrudan etkisi bulunan lojistik faaliyetleri, turizm sektöründe sadece taşıma hizmetleri şeklinde nitelendirilememektedir. Turistlerin tatillerini yapacakları destinasyonlara gidiş ve dönüş yolculukları ve tatilleri süresince gerçekleştirecekleri transferler güvenli, konforlu ve kaliteli şekilde gerçekleştirilmelidir. Aksi durumda turistik talebi doğrudan etkilemekle birlikte, gelir azalmasına ve gelecek dönemlerde olumsuz etkilere yol açabilecektir. $\mathrm{Bu}$ nedenle seyahat acentalarının lojistik performans kritelerinin belirlenmesini içeren ideal lojistik faaliyetlerinin hangi unsurlardan oluştuğunun tespiti önem arz etmektedir. Çalışmanın araştırma bölümünde seyahat acentalarının lojistik performansı ile ilgili kriterlerin belirlenmesi yapılarak, araştırma sonuçları ortaya konmaktadir.

Yapılan literatür taramasında lojistik performans faktörlerinin önem derecelerinin belirlenmesi ve en ideal seyahat acentası seçimine ilişkin başka bir çalışma tespit edilmemiştir. Bu olgu, çalışmanın önemini artıran bir unsur olarak düşünülmektedir. Ayrıca lojistik performans faktörleri ile en ideal seyahat acentası seçimi konusunda DEMATEL-GİA bütünleşik yaklaşımlarının kullanıldığı bir çalışmaya da rastlanmamıştır. Bu nedenle bu çalışmanın literatüre katkı sağlayacağı değerlendirilmektedir.

\section{ARAŞTIRMANIN YÖNTEMI}

Giresun'da seyahat acentalarında lojistik performans unsurlarının belirlenmesinde Çok Kriterli Karar Verme (ÇKKV) yöntemi olan Dematel'den yararlanılmış ve kriter ağırlıkları Dematel ile belirlenmiştir. Belirlenen kriter ağırlıkları kullanılarak GİA yöntemi ile en ideal seyahat acentası seçimi yapılmıştır.

\section{Dematel Yöntemi}

DEMATEL yöntemi Cenevre BattelleMemorial Enstitüsü tarafindan ortaya konulan çok kriterli karar verme yaklaşımıdır (Wu vd., 2010, 5220). Wu ve Tsai, (2011) ise yöntemi; karışık problem kümesindeki unsurların birbirleri arasındaki karşılıklı ilişkilerini tespit etmek ve tespit edilen bu ilişkiler kapsamında birbirleri üzerindeki etkiyi önceliklendirmek için yapısal bir model geliştirmeye yönelik çalışmalar olarak ifade etmişlerdir. vermiştir.

Wu ve Tsai (2011) ve Erdal (2017), DEMATEL yönteminin adımlarını aşağıda

\section{Adım 1: Direkt İlişki Matrisinin Oluşturulması ve Ortalama Direkt İlişki Matrisinin Elde Edilmesi}

Direkt ilişki matrisi; kriterler arasındaki ikili karşılaştırmalar yapılarak karar verici/uzman grup tarafından belirlenir. $\mathrm{Bu}$ çalışmada literatürde yaygın olarak 
kullanılan Dey vd. (2012)'in karşılaştırma ölçeğinden istifade edildiğinden Dey vd. (2012)'in ölçeği Tablo 1'de sunulmuştur (Dey vd., 2012, 3560-3562).

Tablo 1. DEMATEL Metodu İçin Karşılaştırma Skalası

\begin{tabular}{|l|l|}
\hline Sayısal Değer & Sözel İfade \\
\hline 0 & Etkisiz \\
\hline 1 & Düşük Etkili \\
\hline 2 & Orta Etkili \\
\hline 3 & Yüksek Etkili \\
\hline 4 & Çok Yüksek Etkili \\
\hline
\end{tabular}

Bu adımda uzmanlardan Tablo 1'deki ölçeğe göre; "Hangi kriter hangi kriteri ne düzeyde etkiliyor?" sorusuna cevap vermesi istenerek her bir uzmanın değerlendirmelerine göre $\mathrm{k}$ adet $\mathrm{nxn}$ boyutlu direkt ilşki matrisi oluşturulur. Direkt ilişki matrisi simetrik değildir ve köşegen elemanları 0'dır. Bu matrisin her (i,j) elamanı kriter i'den kriter j'ye olan direk ilişskiyi gösterir.

Elde edilen $\mathrm{k}$ adet direkt ilişki matrisinin Denklem (1) kullanılarak ortalaması alınır ve ortalama direkt ilişki matrisi (X) oluşturulur. Bu aynı zamanda grup kararıdır.

$$
\begin{gathered}
a_{i j}=\frac{1}{k} \sum_{n=1}^{k} x_{i j}^{n} \\
X=\left[\begin{array}{cccc}
0 & x_{11} & \ldots & x_{1 n} \\
x_{21} & 0 & \ldots & x_{2 n} \\
\vdots & \vdots & \ddots & \vdots \\
x_{n 1} & x_{n 2} & \ldots & 0
\end{array}\right]
\end{gathered}
$$

\section{Adım 2: Normalleştirilmiş Direkt İlişki Matrisinin Oluşturulması}

Denklem (2) ve (3) kullanılarak normalleştirilmiş direkt ilişki matrisi (C) oluşturulur. $x_{i j}$ elemanları yerine $a_{i j}$ elemanları yazılır. (X) matrisin satır ve sütün toplamları içinden en büyüğü belirlenerek ortalama direkt ilişki matrisi bu değere bölünür.

$$
\begin{gathered}
s=\operatorname{maks}\left(\operatorname{maks} \sum_{j=1}^{n} x_{i j}, \operatorname{maks} \sum_{i=1}^{n} x_{i j}\right) \\
C=\frac{X}{S}
\end{gathered}
$$

(X) matrisinin satır toplamları, satırdaki her bir kriterin diğerleri üzerindeki toplam etkisini gösterdiğinden Denklem (2)'de yazılan ifadelerden ilki diğerleri üzerinde en fazla etkisi olan kriterin toplam etkisini gösterecektir. Benzer şekilde her i sütununun toplamı i kriterinin üzerindeki toplam etkiyi göstermektedir. Bu değerlerden maksimuma sahip olan ise en fazla etkiyi gösterendir. İki değerden en büyük olanı seçip her elemanı bu değere böldüğümüzde de (C) matrisi elde edilir ve bu matrisin elemanları 0-1 arasında bir değer alır. 


\section{Adım 3: Toplam İlişki Matrisinin Oluşturulması}

Toplam ilişki matrisinin (F) oluşturulabilmesi için Denklem (4) ve (5) kullanılır. Bu denklemlerde $I$ nxn boyutundaki birim matrisi, (C)'ler ise giderek azalan dolaylı etkileri ifade eder.

$$
\begin{gathered}
\lim _{k \rightarrow \infty} c+c^{2}+c^{3}+\ldots+c^{k} \\
F=C+C^{2}+C^{3}+\ldots+C^{k}=C(I-C)^{-1}
\end{gathered}
$$

\section{Adım 4: Etkilen ve Etkileyen (Gönderici ve Alıcı) Kriter GruplarınınBelirlenmesi}

Bir önceki adımda elde edilen (F) matrisinden yola çıkarak; bu matrisin i'inci satırının toplamı $\left(D_{i}\right)$, i kriteri tarafından diğer kriterlere gönderilen etkilerin (doğrudan ve dolaylı) toplamını gösterir. Sütun toplamı $\left(R_{i}\right)$ ise aynı kriter için diğer kriterlerden gelen etkilerin toplamını ifade eder.

Her kriter için satır ve sütun toplamlarıyla elde edilen $\left(D_{i}+R_{i}\right)$ değeri gönderilen ve alınan toplam etki değerini; $\left(D_{i}-R_{i}\right)$ değeri ise i faktörünün bütüne yaptığı net etkiyi göstermektedir. Bu değerin pozitif olması i kriterinin "net etkileyen", negatif olması ise "net etkilenen" olduğunu ifade eder. Daha açık bir ifadeyle; $\left(D_{i}\right)$ gönderilen etkileri, $\left(R_{i}\right)$ alınan etkileri; $\left(D_{i}+R_{i}\right)$ merkezi rol derecesini ve son olarak da $\left(D_{i}-\right.$ $R_{i}$ ) etki derecesini ifade eder.

$\left(D_{i}+R_{i}\right)$ değerleri kriterlerin ne kadar önem derecelerine sahip olduğunu gösterirken, $\left(D_{i}-R_{i}\right)$ değerleri kriterleri gönderici ve alıcı gruplar olarak ikiye ayırır. Genel olarak $\left(D_{i}-R_{i}\right)$ değerlerinden negatif olanlar alıcı (etkilenen) grubu, pozitif olanlar ise gönderici (etkileyen) grubu oluşturur.

\section{Adım 5: Eşik Değerin Hesaplanması ve Etki Diyagramının Çizilmesi}

Eşik değerin karar vericiler (veya uzmanlar) tarafından doğrudan belirlenmesi klasik ve yaygın bir yaklaşımdır. Ancak bazı karar problemleri için görüşlerine başvurulan karar verici sayısının çok olması nedeniyle eşik değerin tespiti zorlaşabilmektedir. Eşik değerin elde edilmesi için bir diğer yaygın kullanım bu çalışmada da kullanıldığı şekilde durulaştırılmış toplam ilişki matrisinin aritmetik ortalamasının alınmasıdır. Belirlenen eşik değeri elde edilmiş olan diyagramın karmaşıklığını engellemek için gereklidir. Kullanılacak eşik değerinin büyük veya küçüklüğü kriterlerin birbirleri üzerindeki etkileşiminin boyutuna tesir edebilmekte ve çözümün karmaşıklığı ve basitliğini sağlayabilmektedir.

Etki diyagramı, yatay ekseni $\left(D_{i}+R_{i}\right)$, düşey ekseni $\left(D_{i}-R_{i}\right)$ olan bir koordinat düzleminde $\left[\left(D_{i}+R_{i}\right),\left(D_{i}-R_{i}\right)\right]$ noktalarının gösterilmesiyle elde edilir.

\section{Adım 6: Kriter Ăgırlıklarının Belirlenmesi}

Denklem (15) ve (16) kullanılarak öncelikler belirlenir.

$$
\begin{gathered}
\mathrm{w}_{\mathrm{i}}=\sqrt{\left[\left(D_{i}+R_{i}\right)\right]^{2}+\left[\left(D_{i}-R_{i}\right)\right]^{2}} \\
\mathrm{~W}_{\mathrm{i}}=\frac{w_{i}}{\sum_{i=1}^{n} w_{i}}
\end{gathered}
$$




\subsection{GİA Yöntemi}

Deng (1989) tarafindan geliştirilen Gri Sistem Teorisi kapsamında geliştirilen GİA, gri sayılar ve gri değişkenlerle temsil edilen bilinmeyen bilgiyi içeren bir sistem olarak tanımlanmaktadır (Chou ve Tsai, 2009:201). Baş (2010), çalışmasında GİA'y1 derecelendirme ve sıralama amaçlarına yönelik olarak kullanılan bir karar verme tekniği olduğunu söylemiş ve karmaşık hesaplamalar ve formüllere ihtiyaç duymaması ile net hesaplama süreçlerinden oluşan yöntemin son yıllarda farklı alanlarda kullanılmaya başladığını ifade etmiştir.

GİA uygulama adımları aşağıda verilmiştir (Zhai vd., 2009: 7074):

1. Alternatiflerin $(i=1, . ., m)$ ve kriterlerin $(j=1, . ., n)$ Belirlenmesi.

$$
\chi_{i}=\left(\chi_{i}(1), \chi_{i}(2), \chi_{i}(3), \ldots \ldots \ldots, \chi_{i}(n)\right)
$$

2. Karşılaştırılabilir Serilerin En Düşük (Minimum) veya En Büyük (Maksimum) Değerlerine Dayalı Olarak Referans Serilerin Oluşturulması

$$
\chi_{\mathrm{o}}=\left(\chi_{0}(1), \chi_{0}(2), \chi_{0}(3), \ldots \ldots . ., \chi_{0}(\mathrm{n})\right)
$$

3. Değerlerin Birim Etkisinden Arındırılmasına Olanak Sağlayan Normalleştirme

\section{İşleminin Gerçekleştirilmesi}

Bu süreç, aşağıda belirtildiği gibi üç şekilde olabilir:

Daha düşük daha iyi: $\quad \chi_{\mathrm{i}}(\mathrm{k})=\frac{\max \chi_{\mathrm{i}}^{0}(\mathrm{k})-\chi_{\mathrm{i}}^{0}(\mathrm{k})}{\max \chi_{\mathrm{i}}^{0}(\mathrm{k})-\min \chi_{\mathrm{i}}^{0}(\mathrm{k})}$

Daha yüksek daha iyi: $\quad \chi_{\mathrm{i}}(\mathrm{k})=\frac{\chi_{\mathrm{i}}^{0}(\mathrm{k})-\min \chi_{\mathrm{i}}^{0}(\mathrm{k})}{\max \chi_{\mathrm{i}}^{0}(\mathrm{k})-\min \chi_{\mathrm{i}}^{0}(\mathrm{k})}$

İdeal değere daha iyi: $\quad \chi_{\mathrm{i}}(\mathrm{k})=1-\frac{\left|\chi_{\mathrm{i}}^{0}(\mathrm{k})-\chi^{0}\right|}{\max \chi_{\mathrm{i}}^{0}(\mathrm{k})-\chi^{0}}$

$x_{i}(k) \quad$ ve $\quad x_{i}^{0}(k)$ sırasıyla normalleştirme sonrası ve önceki değeri gösterirken $\min x_{i}^{0}(k)$ ve $\max x_{i}^{0}(k)$ da k'nıncı cevaplayıcının sırasıyla normalleştirme öncesi en düşük ve en büyük değerlerini göstermektedir.

4. Referans Seriler İle Alternatif Seriler Arasındaki Benzerliğin Bir Göstergesi Olarak Gri İlişkisel Katsayı Değerlerinin Hesaplanması

$$
\varepsilon\left(\chi_{0}(\mathrm{k}), \chi_{\mathrm{i}}(\mathrm{k})\right)=\frac{\Delta_{\min }+\xi \Delta_{\max }}{\Delta_{\mathrm{oi}}(\mathrm{k})+\xi \Delta_{\max }}
$$




\section{Referans Serilere Benzerliklerine Göre Alternatiflerin Sıralanmasında}

\section{Kullanılmak Üzere Gri İlişkisel Derece Değerlerinin Hesaplanması}

$\mathrm{Bu}$ hesaplama aşaması, kriterlerin eşit (14) ve farklı (15) derecede öneme sahip olması durumlarına göre aşağıdaki denklemler yardımıyla hesaplanmaktadır:

$$
\begin{aligned}
& \gamma\left(\chi_{0}, \chi_{\mathrm{i}}\right)=\frac{1}{\mathrm{n}} \sum_{\mathrm{k}=1}^{\mathrm{n}} \varepsilon\left(\chi_{\mathrm{o}}(\mathrm{k}), \chi_{\mathrm{i}}(\mathrm{k})\right) \\
& \gamma\left(\chi_{0}, \chi_{\mathrm{i}}\right)=\sum_{\mathrm{k}=1}^{\mathrm{n}} \mathrm{w}_{\mathrm{i}}(\mathrm{k}) \varepsilon\left(\chi_{\mathrm{o}}(\mathrm{k}), \chi_{\mathrm{i}}(\mathrm{k})\right)
\end{aligned}
$$

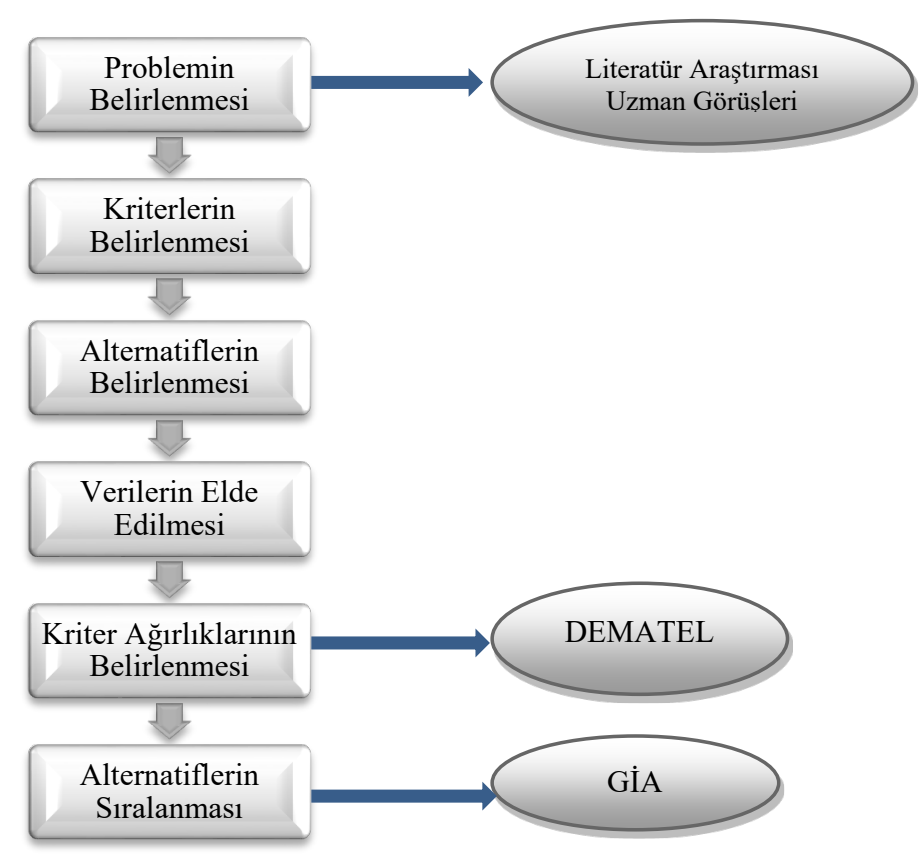

Şekil 1: Bütünleşik Dematel-GíA Uygulama Adımları

\section{UYGULAMA}

Çalışmada Giresun ili'nde faaliyet gösteren seyahat acentalarının lojistik performans unsurlarında kullanılacak kriterlerin değerlendirilmesi için çok kriterli karar modeli oluşturulmuştur. Şekil 1'de verilen modelin adımları uygulanmıştır. Modele göre öncelikle uzman görüşleri ile literatür taramasından faydalanılarak seyahat acentalarındaki lojistik performans unsurlarına ilişkin kriterler belirlenmiştir. Belirlenen kriterler eşit öneme sahip olmadığından kriterlerin ağırlıklandırılmasına ihtiyaç duyulmuştur. $\mathrm{Bu}$ kapsamda Dematel yöntemi ile seyahat acentalarındaki lojistik performans unsurları ağırlıklandırılmıştır. Kriterler belirlenirken uzman görüşleri, literatür taraması, akademisyenler, Sanayi ve Ticaret Odası yetkilileri ile seyahat acentası yöneticilerinden faydalanılarak aşağıdaki tablo oluşturulmuştur (Chov vd., 
1994; Cabanis, 1995; Lai vd., 2002 ; Melnyk vd., 2004; Bayraktutan ve Özbilgin, 2015; Gergin ve Baki, 2015 )

Tablo 2. Karar Kriterleri

\begin{tabular}{|l|}
\hline \multicolumn{1}{|c|}{ Ana Kriterler } \\
\hline Destinasyon Güvenliği $\left(\mathrm{K}_{1}\right)$ \\
\hline Taşıma Maliyetleri ve Güvenliği $\left(\mathrm{K}_{2}\right)$ \\
\hline Seyahat Talebi ve İzlenebilirliği $\left(\mathrm{K}_{3}\right)$ \\
\hline Bilgi ve İşletim Altyapısı $\left(\mathrm{K}_{4}\right)$ \\
\hline Seyahat Gecikme Süresi $\left(\mathrm{K}_{5}\right)$ \\
\hline $\begin{array}{l}\text { Gümrük İşlemleri (Isşlem Kolaylığı ve hızı, Şeffaflık vb.) } \\
\left(\mathrm{K}_{6}\right)\end{array}$ \\
\hline Taşıma Kolaylığı $\left(\mathrm{K}_{7}\right)$ \\
\hline Seyahat Süresi $\left(\mathrm{K}_{8}\right)$ \\
\hline Ticaret Altyapısı $\left(\mathrm{K}_{9}\right)$ \\
\hline Seyahat Hizmet Kalitesi $\left(\mathrm{K}_{10}\right)$ \\
\hline
\end{tabular}

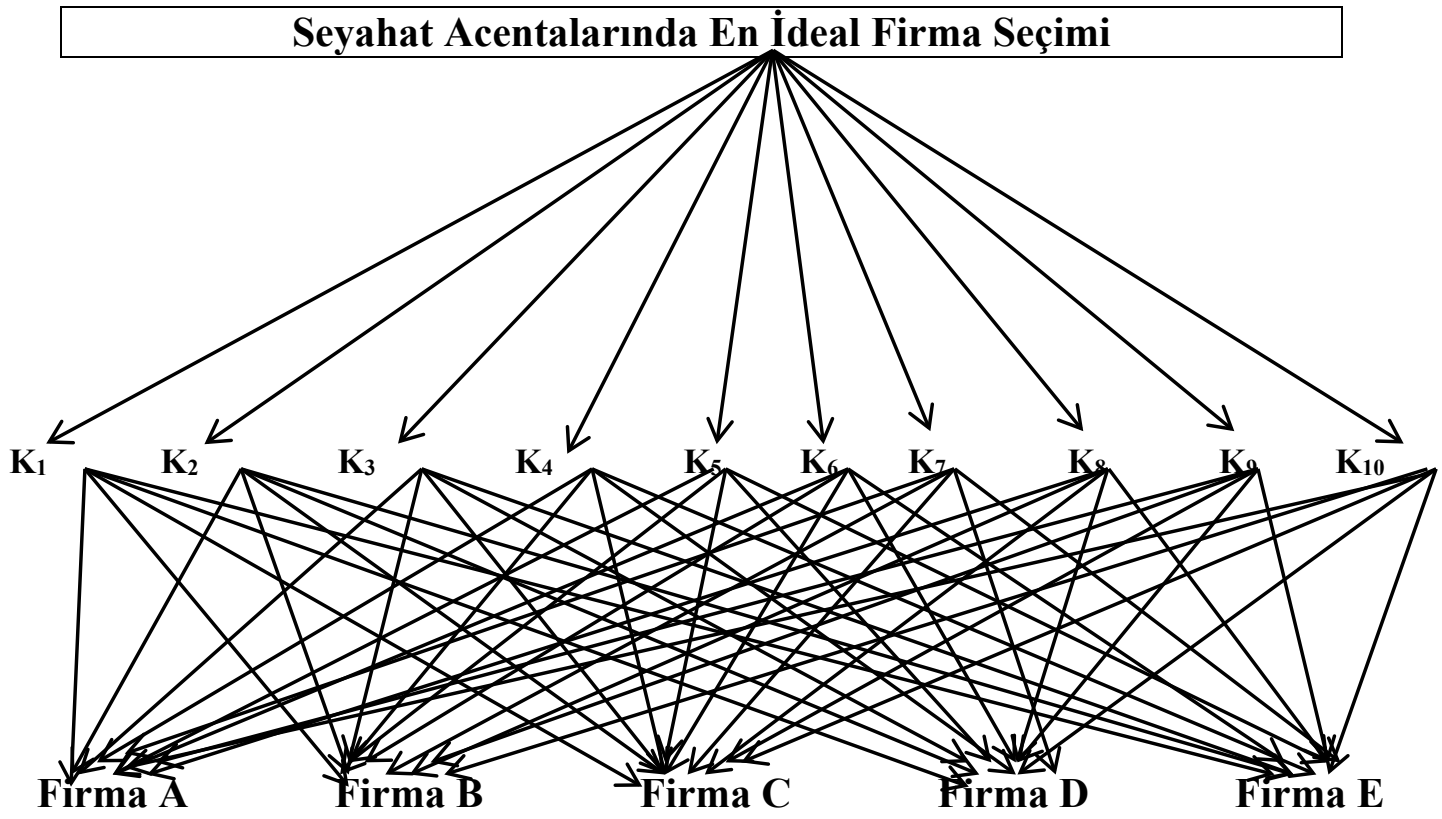

Şekil 2. Hiyerarşik Yapı

\section{Kriterlerin Ağırlıklandırılması}

Dematel yönteminden faydalanılan bu aşamada kriterlerin değerlendirilmesi için karar matrisi oluşturulmuştur. Konunun paydaşları olan akademisyenlere (4), işletme yöneticilerine (9), Ticaret ve Sanayi Odası yetkililerine (4) toplamda 17 anket 
sunulmuştur. Görüşlere ilişkin tablolar Ekler kısmında sunulmuştur. Bu doğrultuda kriterlerin ağırlıklandırılmasına yönelik olarak Dematel ile ağırlıklar belirlenmiş ve Tablo 3'te yer alan kriter ağırlıkları elde edilmiştir.

Tablo 3. Kriter Ağırlıkları Tablosu

\begin{tabular}{|c|c|c|c|c|c|c|c|c|c|c|}
\hline & $\mathbf{K}_{\mathbf{1}}$ & $\mathbf{K}_{\mathbf{2}}$ & $\mathbf{K}_{\mathbf{3}}$ & $\mathbf{K}_{\mathbf{4}}$ & $\mathbf{K}_{\mathbf{5}}$ & $\mathbf{K}_{\mathbf{6}}$ & $\mathbf{K}_{\mathbf{7}}$ & $\mathbf{K}_{\mathbf{8}}$ & $\mathbf{K}_{\mathbf{9}}$ & $\mathbf{K}_{\mathbf{1 0}}$ \\
\hline Ăğırlık & 0,109 & 0,099 & 0,097 & 0,104 & 0,098 & 0,091 & 0,085 & 0,090 & 0,093 & 0,134 \\
\hline
\end{tabular}

Tablo 3'e göre seyahat acentalarında lojistik performans unsurları için en önemli kriterlerin sırası ile "Seyahat Hizmet Kalitesi", "Destinasyon Güvenliği" ve "Bilgi ve İletişim Altyapısı" olduğu saptanmıştır. Öte yandan en az öneme sahip kiriterlerin ise sırasıyla "Taşıma Kolaylığı”, "Seyahat Süresi”, "Gümrük İşlemleri”, "Ticaret Altyapısı", "Seyahat Talebi ve İzlenebilirliği”, " Seyahat Gecikme Süresi” ve "Taşıma Maliyetleri ve Güvenliğii” olduğu tespit edilmiştir.

\section{Alternatiflerin Sıralanması}

$\mathrm{Bu}$ bölümde en ideal seyahat acantesi seçimi için GİA tekniğinden yararlanılmıştır. Dematel yöntemi ile elde edilen kriterlerin ağırlıkları kullanılarak GİA tekniği ile seyahat acentelerinin yani alternatiflerin sıralaması yapılmıştır. Daha önceden belirlenen karar kriterleri çerçevesinde her bir alternatifin değerlendirilmesi GİA anketi ile yapılmıştır. Değerlendirme esnasında katılımcılardan her bir alternatife 1-5 (1-en kötü, 5 en iyi) arasında puan vermeleri istenmiştir. Bu kapsamda karar matrisi oluşturulmuş ve sonrasında karar matrisi normalleştirilmiştir. Görüşlere ilişkin tablolar Ekler kısmında sunulmuştur. Öncelikli olarak ölçüt önem düzeylerine göre alternatifler sıralanmış ve Tablo 4. de sunulmuştur.

Tablo 4. Ölçüt Önem Düzyelerine Göre Gri İlişki Dereceleri ve Sıralama

\begin{tabular}{|l|c|c|c|c|c|}
\hline & Firma A & Firma B & Firma C & Firma D & Firma E \\
\hline $\boldsymbol{\Gamma}_{\mathbf{0} \text { i }}$ & 0,533 & 0,600 & 0,633 & 0,733 & 0,416 \\
\hline Siralama & 4 & 3 & 2 & 1 & 5 \\
\hline
\end{tabular}

Tablo 4'e göre ölçüt önem düzeylerine göre en ideal seyahat acentası seçimi firma sıralamasında "Firma D" en iyi alternatif olmuştur. Öte yandan diğer firmalar için ise sıralama $\mathrm{C}>\mathrm{B}>\mathrm{A}>\mathrm{E}$ şeklinde gerçekleşmiştir.

Öte yandan Dematel yöntemi ile belirlenen ağırlıklar ile yapılan seyahat acentalarında en ideal firma seçimi için ise sıralama aşağıdaki tabloda verilmiştir.

Tablo 5. Dematel Ağırıkları İle Gri İlişki Dereceleri ve Sıralama

\begin{tabular}{|l|c|c|c|c|c|}
\hline & Firma A & Firma B & Firma C & Firma D & Firma E \\
\hline $\boldsymbol{\Gamma}_{\mathbf{0} \mathbf{i}}$ & 0,520 & 0,683 & 0,643 & 0,757 & 0,413 \\
\hline Siralama & 4 & 2 & 3 & 1 & 5 \\
\hline
\end{tabular}

Tablo 5'e göre en ideal seyahat acentası seçimi firma sıralamasında Dematel ile belirlenen ağırlıklar göz önüne alındığında en iyi alternatifin "Firma D" seçeneği olduğu tespit edilmiştir. Diğer taraftan Dematel yöntemine göre sıralama $\mathrm{B}>\mathrm{C}>\mathrm{A}>\mathrm{E}$ şeklinde gerçekleşmiştir.

Tablo 4 ve Tablo 5'te belirtilen her iki sıralamada "Firma D" seçeneği en iyi alternatif olmuştur. "Firma A" ve "Firma E" ise her iki uygulamada son sırayı alan diğer 
alternatiflerdir. Ölçüt önem düzeyleri ve Dematel Ağırlıklandırılması ile yapılan her iki sıralamada benzer sonuçlara ulaşılmış bu olgu da analizlerin güvenilirliğini artırmıştır.

\section{SONUÇ VE ÖNERILER}

Lojistik performans faktörleri, her sektörde önemli olan ve rekabet avantaj1 sağlayan unsurlar olmakla birlikte firmalara müşteri memnuniyeti sağlayan ve müşteri devamlılığ 1 getiren anahtar bileşenlerdir. Bu bileşenler turizm alanında faaliyet gösteren seyahat acentaları için de önemli bir çerçeve çizmekte ve sürdürülebilir rekabet ve verimliliği sağlamada kritik rol oynayan unsurlar olarak düşünülmektedir.

Çalışmada, ÇKKV yöntemlerinden DEMATEL ve GİA yöntemlerinden yararlanılarak, lojistik performans faktörleri önceliklendirilmiş ve belirlenen ağırlıklar kullanılarak en ideal seyahat acentası seçimi yapılmıştır. Bu değerlendirmede lojistik performans unsurları "Seyahat Hizmet Kalitesi", "Destinasyon Güvenliği" , "Bilgi ve İletişim Altyapısı" , “Taşıma Kolaylığı”, "Seyahat Süresi”, "Gümrük İşlemleri”, "Ticaret Altyapısı", "Seyahat Talebi ve İzlenebilirliğii”, " Seyahat Gecikme Süresi” ve "Taşıma Maliyetleri ve Güvenliği” olmak üzere toplam on kriter dikkate alınarak yapılmıştır. Daha sonra kriterlerdeki ağırlıklar kullanılarak Giresun İli için en ideal seyahat acentası seçimi yapılmış ve sıralanmıştır.

$\mathrm{Bu}$ çerçevede seyahat acentalarında en önemli lojistik performans kriterlerinin "Seyahat Hizmet Kalitesi", "Destinasyon Güvenliğii" ve "Bilgi ve İletişim Altyapısı" olduğu tespit edilmiştir. Bu sonuçların; Hanaoka ve Kunadhamraks (2009), Fugute vd., (2010) ve Hsiao vd., (2010) çalışmaları ile örtüştüğü tespit edilmiştir. Öte yandan en az öneme sahip olan diğer kriterlerin ise , "Taşıma Kolaylığı", "Seyahat Süresi”, "Gümrük İşlemleri", "Ticaret Altyapısı", "Seyahat Talebi ve İzlenebilirliği”, "Seyahat Gecikme Süresi” ve "Taşıma Maliyetleri ve Güvenliği “ olduğu belirlenmiştir. Tespit edilen sonuçların Korpela ve Tuominen (1996), Fawcett ve Cooper (1998), Lai vd., (2002), Liu ve Lyons, (2011) ve Lee ve Lam (2012) çalışmaları ile benzeştiği ancak SchrammKlein ve Morschett (2006), ve Wang (2015) çalışmaları ile benzeşmediği saptanmıştır.

İlerleyen aşamada GİA yöntemi ile en ideal seyahat acentası seçimi yapılmıştır. GİA yöntemi sonuçlarına göre; DEMATEL yöntemi ile belirlenen ağırlıklar kullanılarak "Firma D" alternatifinin en ideal seyahat acentası olduğu tespit edilmiştir.

İlgili literatür tarandığında seyahat acentalarında lojistik performans faktörlerinin Dematel yöntemiyle önceliklendirilmesi ve bütünleşik Dematel-GİA yöntemleri ile en ideal seyahat acentası seçimiyle ilgili herhangi bir çalışmanın olmaması literatüre katkı sağlaması bakımından önemli bir unsur olmak birlikte çalışmayı diğer çalışmalardan farklı kılan etkenler olduğu düşünülmektedir. $\mathrm{Bu}$ bakımdan çalışma, seyahat acentalarının çeşitli açılardan değerlendirilmesine / karşılaştırılmasına örnek teşkil edecek yapıdadır.

Çalışmanın sonucunda elde edilen verilere kriterler açısından bakıldığında, seyahat acentalarında lojistik performans faktörlerini artırmaya yönelik düzeltici ve düzenleyici iyileştirmelere ihtiyaç duyulmaktadır. Gerekli iyileştirmelerin ivedi bir şekilde gerçekleştirilmesi, müşteri memnuniyeti ve tatmini açısından önem arz etmekle birlikte firmalar için maliyeti azaltan aynı zamanda firma kârlılığını artıran bir unsur olarak karşımıza çıkmaktadır.

Diğer taraftan seyahat acentaları gerçekleştirdiği etkinliklerde (rezervasyon ve bilgilendirme yapmak, kongre ve konferans organizasyonları gerçekleştirmek, araç 
kiralamak, bilet satışı yapmak, otel tanıtımı yapmak vb.) lojistik faaliyetlerden sürekli olarak yararlanmakta ancak lojistik faaliyetlerin önemini firma düzeyinde yeterince idrak edememektedir. Aslında seyahat acentalarının yapmış olduğu iş ve işlemlerin çoğu lojistik performans unsurlarına göre şekillenmekte, bu unsurlara yeterince önem verilmediğinden verimlik ve etkinlik noktasında düşük çıktılar alınmaktadır. $\mathrm{Bu}$ kapsamda seyahat acentası yöneticileri ve çalışanları lojistik ve lojistik performans unsurlarına daha fazla odaklanmalı, konunun önemi ve uygulanabilirliği üzerine daha fazla çaba sarf etmelidir.

Küresel ve yerel boyutta rekabet şansını yakalamanın temel göstergelerinden biri olan lojistik performans faktörlerinin seyahat acentalarında etkinlik kazanmasında eğitim de önemli bir bileşendir. Gerek devlet destekleri gerekse özel sektör yönlendirmeleri ile seyahat acentası çalışanlarına daha çok lojistik ve lojistik performansın önemi hakkında eğitimler verilmeli ve verilen eğitimlerin çıktı düzeyleri incelenmelidir.

$\mathrm{Bu}$ çalışmada konunun tarafları olduğu düşünülen uzmanlar ile görüşülmüş; ancak zaman kısıtı nedeniyle bu sayı artırılamamıştır. Öte yandan bu çalışmada ele alınan problem başka alanlara da uygulanabilir. Ayrıca söz konusu çalışma gelecekte diğer çok kriterli karar verme ve / veya parametrik veya parametrik olmayan diğer yöntemler ile bulanık mantık ilave edilerek geliştirilebilir ve sonuçlar kıyasalanarak tartışılabilir.

\section{KAYNAKLAR}

Baş, M. (2010), "İşletmelerde Finansal Başarısızlı̆̆ın Öngörülmesinde Gri İlişkisel Analiz Tekniği, Tekstil ve Deri Sektöründe Bir Uygulama”, Dumlupınar Üniversitesi Sosyal Bilimler Enstitüsü, Yayınlanmamış Doktora Tezi, Kütahya.

Bayraktutan, Yusuf ve Özbilgin, Mehmet. (2015). Lojistik Maliyetler ve Lojistik Performans Ölçütleri, Maliye Araştırmaları Dergisi, Yı1:1, Cilt:1, Sayı:2, 95112.

Bezirci, M. ve Dündar, A. O. (2011). Lojistik Köylerin İşletmelere Sağladığı Maliyet Avantajları, Trakya Üniversitesi Sosyal Bilimler Dergisi. 13(1), 292-307.

Bowersox, D. J. (1997). Integrated Supply Chain Management: A Strategic Imperative, in Annual Conference Proceedings, Council of Logistics Management, Chicago, Illinois, 181-189.

Cabanis, R.F.,(1995). "Comparing Domestic and International Distributors' Performance, A Manufacturer's Perspective”, International Journal of Physical Distribution\&Logistics Management, Vol.25, No.6, 41-53.

Canıtez, M.\& Tümer, G.(2005). İthalat ve İhracatta Lojistik, Uygulamalı İthalat İhracat ve Dokümantasyon, 3.Baskı Gazi Kitabevi, Ankara.

Chou, Jhy-Rong ve Tsai, Hung-Cheng (2009). "On-Line Learning Performance and Computer Anxiety Measure for Unemployed Adult Novices Using a Grey Relation Entropy Method", Information Processing And Management, 45, 200215. 
Chow, G., Heaver, T.D., Henriksson, L.E., (1994). "Logistics Performance: Definition and Measurement", International Journal of Physical Distribution \&Logistics Management Vol 24 No 1,17-28.

CLIA, (2017). 2018 Cruise Industry Outlook, Cruise Lines International Assocation, Clia Global, Washington.

Çakır, Süleyman ve Perçin, Selçuk. (2013). Çok Kriterli Karar Verme Teknikleriyle Lojistik Firmalarında Performans Ölçümü, Ege Akademik Bakış, Cilt: 13, Sayı: 4, 449-459.

Çanc1, M. ve Erdal, M. (2003). Lojistik Yönetimi. UTİKAD yayınları, İstanbul.

Çolakoğlu, O. E. ve Çolakoğlu, Ü. (2007). Seyahat Acentaları Yönetimi, Detay Yayıncilık, Ankara.

Dey, S., Kumar, A., Ray, A., and Pradhan, B. B. (2012). "Supplier Selection: IntegratedTheory Using DEMATEL and Quality Function Deployment Methodology". Procedia Engineering, 38, 3560-3565.

Erdal, H. (2017). “Tedarik Zinciri Ağında Riskin Yönetimi: Tedarik Yönlü Bir Karar Destek Sistemi Tasarımı”, (Yayımlanmamış Doktora Tezi), Atatürk Üniversitesi Sosyal Bilimler Enstitüsü, Erzurum.

Fawcett, S. E., Cooper, M. B. (1998). "Logistics Performance Measurement and Customer Success", Industrial Marketing Management,Vol.27, No:4, 341-357.

Fugate, B. S., Autry, C. W., Davis-Sramek, B., Germain, R. N. (2012). "Does Knowledge Management Facilitate Logistics-Based Differentiation? The Effect of Global Manufacturing Reach", International Journal of Production Economics, Vol.139, No.2, 496-509.

Gergin, R,E, ve Baki, B, (2015).” Türkiye'de Bölgelerin Lojistik Performanslarının Bütünleştirilmiş AHS-TOPSIS Yöntemiyle Değerlendirilmesi”, Business and Economics Research, Journal Volume 6 Number 4, 115-136.

Hanaoka, S., ve Kunadhamraks, P. (2009). "Multiple Criteria and Fuzzy Based Evaluation of Logistics Performance for Intermodal Transportation", Journal of Advanced Transportation, Vol.43, No.2, 123.

Hsiao, H., Kemp, R. G. M., Van der Vorst, J. G. A. J., Omta, S. O. (2010). "A Classification of Logistic Outsourcing Levels and Their Impact on Service Performance: Evidence From The Food Processing Industry", International Journal of Production Economics, Vol.124, No.1, 75-86.

Korpela, J., Tuominen, M. (1996). "Benchmarking Logistics Performance with an Application of The Analytic Hierarchy Process", Engineering Management, IEEE Transactions on, Vol.43, No.3, 323-333.

Lai, K., Ngai, E.W.T., Cheng, T.C.E.(2002). "Measures for Evaluating Supply Chain Performance in Transportation Logistics", Transportation Research Part E, Vol.38, 449-456.

Lambert, Douglas M., James R. Stock and Lisa M. Ellram. (1998). Fundamentals of Logistics Management, Irwin McGraw-Hill, USA. 
Landers, Thomas L., Alejandro Mendoza and John R. English (2008). "Logistics Metrics", Introduction to Logistics Engineering, Ed. Don Taylor, CRC Press, USA.

Lee, C. K. M., \& Lam, J. S. L. (2012). "Managing Reverse Logistics To Enhance Sustainability Of İndustrial Marketing”, Industrial Marketing Management, Vol.41, No.4, 589598.

Liu, C. L., Lyons, A. C. (2011). "An Analysis of Third-Party Logistics Performance and Service Provision", Transportation Research Part E: Logistics and Transportation Review, Vol.47, No.4, 547-570.

Melnyk, S, A., Douglas M., Stewart, M, S, (2004). "Metrics and Performance Measurement in Operations Management: Dealing With The Metrics Maze", Journal of Operations Management, No.22, 209-217.

Rushton, Alan, John Oxley and Phil Croucher (2000). Handbook of Logistics and Distribution Management, Kogan Page Limited, UK.

Schramm-Klein, H., Morschett, D. (2006).’The Relationship Between Marketing

Performance, Logistics Performance and Company Performance for Retail Companies", International Review of Retail, Distribution and Consumer Research, Vol.16, No.02,

277-296.

UNWTO. (2018). Tourism Highlights: 2018 edition, https://www.eunwto.org/doi/pdf/10.18111/9789284419876, (Erişim Tarihi: 11.09.2018).

Wang, M., Jie, F., Abareshi, A. (2015). "Business Logistics Performance Measurement in Third-Party Logistics: An Empirical Analysis of Australian Courier Firms", International Journal of Business and Information, Vol.10, No.3, 323.

Wild, P. ve Dearing, J. (2000). Development of and Prospects for Cruising in Europe, Maritime Policy and Management, Vol: 27 (4), 315-333.

Wu, H., Chen, H. K. and Shieh, J. (2010). "Evaluating Performance Criteria of Employment Service Outreach Program Personnelby DEMATEL Method, Expert System with Applications, 37, 5219-5223.

$\mathrm{Wu}, \mathrm{H} . \mathrm{H}$. and Tsai Y. N. (2011). "An Integratedapproach of AHP and DEMATEL Methods in Evaluating the Criteria of Auto Spare Parts Industry, International Journal of Systems Science, 1-11.

Zengin, B. (2004). Seyahat Işsletmeleri, Ş. Demirkol ve B. Zengin (Ed.), Değişim Yayınları, Sakarya.

Zhai, Lina Yin-Khoo, Li Pheng-Zhong, Zhao Wei (2009). "Design Concept Evaluation in Product Development Using Rough Sets and Grey Relational Analysis", Expert Systems with Applications, No. 36, 7072-7079. 


\section{EKLER}

EK 1. Kriterlerin Ağırlıklandırılmasında Direkt İlişki Matrisi

\begin{tabular}{|c|c|c|c|c|c|c|c|c|c|c|}
\hline Kriterler & $\mathbf{K}_{\mathbf{1}}$ & $\mathbf{K}_{\mathbf{2}}$ & $\mathbf{K}_{\mathbf{3}}$ & $\mathbf{K}_{\mathbf{4}}$ & $\mathbf{K}_{\mathbf{5}}$ & $\mathbf{K}_{\mathbf{6}}$ & $\mathbf{K}_{\mathbf{7}}$ & $\mathbf{K}_{\mathbf{8}}$ & $\mathbf{K}_{\mathbf{9}}$ & $\mathbf{K}_{\mathbf{1 0}}$ \\
\hline $\mathbf{K}_{\mathbf{1}}$ & 0 & 3 & 4 & 3 & 4 & 3 & 3 & 3 & 1 & 3 \\
\hline $\mathbf{K}_{\mathbf{2}}$ & 4 & 0 & 3 & 1 & 2 & 1 & 3 & 2 & 2 & 3 \\
\hline $\mathbf{K}_{\mathbf{3}}$ & 3 & 3 & 0 & 2 & 3 & 2 & 3 & 3 & 2 & 4 \\
\hline $\mathbf{K}_{\mathbf{4}}$ & 3 & 4 & 3 & 0 & 3 & 4 & 2 & 3 & 3 & 4 \\
\hline $\mathbf{K}_{\mathbf{5}}$ & 3 & 4 & 2 & 3 & 0 & 3 & 3 & 3 & 2 & 4 \\
\hline $\mathbf{K}_{\mathbf{6}}$ & 3 & 3 & 2 & 3 & 2 & 0 & 2 & 1 & 2 & 4 \\
\hline $\mathbf{K}_{\mathbf{7}}$ & 2 & 2 & 1 & 3 & 2 & 2 & 0 & 2 & 3 & 3 \\
\hline $\mathbf{K}_{\mathbf{8}}$ & 4 & 2 & 2 & 3 & 1 & 1 & 4 & 0 & 1 & 3 \\
\hline $\mathbf{K}_{\mathbf{9}}$ & 4 & 1 & 3 & 2 & 2 & 2 & 3 & 2 & 0 & 4 \\
\hline $\mathbf{K}_{\mathbf{1 0}}$ & 3 & 2 & 2 & 2 & 3 & 2 & 1 & 3 & 1 & 0 \\
\hline
\end{tabular}

EK 2. Kriterlerin Ağırlıklandırılmasında Normalleştirilmiş Direkt İlişki Matrisi

\begin{tabular}{|c|c|c|c|c|c|c|c|c|c|c|}
\hline Kriterler & $K_{1}$ & $\mathbf{K}_{2}$ & $\mathbf{K}_{3}$ & $\mathbf{K}_{4}$ & $\mathbf{K}_{5}$ & $\mathbf{K}_{6}$ & $\mathbf{K}_{7}$ & $\mathbf{K}_{8}$ & $\mathbf{K}_{9}$ & $K_{10}$ \\
\hline$K_{1}$ & 0 & 0,094 & 0,125 & 0,094 & 0,125 & 0,094 & 0,094 & 0,094 & 0,031 & 0,094 \\
\hline $\mathbf{K}_{2}$ & $\begin{array}{c}0,12 \\
5\end{array}$ & 0 & 0,094 & 0,031 & 0,063 & 0,031 & 0,094 & 0,063 & 0,063 & 0,094 \\
\hline $\mathbf{K}_{3}$ & $\begin{array}{c}0,09 \\
4\end{array}$ & 0,094 & 0 & 0,063 & 0,094 & 0,063 & 0,094 & 0,094 & 0,063 & 0,125 \\
\hline $\mathbf{K}_{4}$ & $\begin{array}{c}0,09 \\
4\end{array}$ & 0,125 & 0,094 & 0 & 0,094 & 0,125 & 0,063 & 0,094 & 0,094 & 0,125 \\
\hline $\mathbf{K}_{5}$ & $\begin{array}{c}0,09 \\
4\end{array}$ & 0,125 & 0,063 & 0,094 & 0 & 0,094 & 0,094 & 0,094 & 0,063 & 0,125 \\
\hline $\mathbf{K}_{6}$ & $\begin{array}{c}0,09 \\
4\end{array}$ & 0,094 & 0,063 & 0,094 & 0,063 & 0 & 0,063 & 0,031 & 0,063 & 0,125 \\
\hline $\mathbf{K}_{7}$ & $\begin{array}{c}0,06 \\
3\end{array}$ & 0,063 & 0,031 & 0,094 & 0,063 & 0,063 & 0 & 0,063 & 0,094 & 0,094 \\
\hline $\mathbf{K}_{8}$ & $\begin{array}{c}0,12 \\
5\end{array}$ & 0,063 & 0,063 & 0,094 & 0,031 & 0,031 & 0,125 & 0 & 0,031 & 0,094 \\
\hline K9 & $\begin{array}{c}0,12 \\
5\end{array}$ & 0,031 & 0,094 & 0,063 & 0,063 & 0,063 & 0,094 & 0,063 & 0 & 0,125 \\
\hline$K_{10}$ & $\begin{array}{c}0,09 \\
4\end{array}$ & 0,063 & 0,063 & 0,063 & 0,063 & 0,063 & 0,031 & 0,094 & 0,031 & 0 \\
\hline
\end{tabular}

\section{EK 3. GRİ İişkisel Analiz Karar Matrisi}

\begin{tabular}{|c|c|c|c|c|c|c|c|c|c|c|}
\hline Kriterler & $\mathbf{K}_{\mathbf{1}}$ & $\mathbf{K}_{\mathbf{2}}$ & $\mathbf{K}_{\mathbf{3}}$ & $\mathbf{K}_{\mathbf{4}}$ & $\mathbf{K}_{\mathbf{5}}$ & $\mathbf{K}_{\mathbf{6}}$ & $\mathbf{K}_{\mathbf{7}}$ & $\mathbf{K}_{\mathbf{8}}$ & $\mathbf{K}_{\mathbf{9}}$ & $\mathbf{K}_{\mathbf{1 0}}$ \\
\hline $\mathbf{A}_{\mathbf{1}}$ & 2 & 3 & 2 & 3 & 3 & 2 & 3 & 3 & 3 & 3 \\
\hline $\mathbf{A}_{\mathbf{2}}$ & 4 & 3 & 3 & 3 & 3 & 3 & 4 & 2 & 3 & 3 \\
\hline $\mathbf{A}_{\mathbf{3}}$ & 3 & 4 & 3 & 3 & 4 & 4 & 4 & 3 & 3 & 4 \\
\hline $\mathbf{A}_{\mathbf{4}}$ & 4 & 4 & 4 & 4 & 4 & 4 & 3 & 3 & 3 & 4 \\
\hline $\mathbf{A}_{\mathbf{5}}$ & 2 & 3 & 2 & 3 & 3 & 3 & 3 & 3 & 2 & 3 \\
\hline
\end{tabular}


EK 4. Ölçüt Önem Düzeyine Göre Gri İlişki Dereceleri ve Sıralama

\begin{tabular}{|c|c|c|c|c|c|c|c|c|c|c|c|c|}
\hline Kriterler & $\mathbf{K}_{\mathbf{1}}$ & $\mathbf{K}_{\mathbf{2}}$ & $\mathbf{K}_{\mathbf{3}}$ & $\mathbf{K}_{\mathbf{4}}$ & $\mathbf{K}_{\mathbf{5}}$ & $\mathbf{K}_{\mathbf{6}}$ & $\mathbf{K}_{\mathbf{7}}$ & $\mathbf{K}_{\mathbf{8}}$ & $\mathbf{K}_{\mathbf{9}}$ & $\mathbf{K}_{\mathbf{1 0}}$ & $\boldsymbol{\Gamma}_{\mathbf{0}}$ & $\mathbf{S}_{\mathbf{i r a l a m a}}$ \\
\hline $\mathbf{A}_{\mathbf{1}}$ & 0,333 & 0,333 & 0,333 & 0,333 & 1 & 1 & 0,333 & 0,333 & 1 & 0,333 & 0,533 & 4 \\
\hline $\mathbf{A}_{\mathbf{2}}$ & 1 & 0,333 & 0,500 & 0,333 & 1 & 0,500 & 1 & 1 & 1 & 0,333 & 0,600 & 3 \\
\hline $\mathbf{A}_{\mathbf{3}}$ & 0,500 & 1 & 0,500 & 0,333 & 0,333 & 0,333 & 1 & 0,333 & 1 & 1 & 0,633 & 2 \\
\hline $\mathbf{A}_{\mathbf{4}}$ & 1 & 1 & 1 & 1 & 0,333 & 0,333 & 0,333 & 0,333 & 1 & 1 & 0,733 & 1 \\
\hline $\mathbf{A}_{\mathbf{5}}$ & 0,333 & 0,333 & 0,333 & 0,333 & 1 & 0,500 & 0,333 & 0,333 & 0,333 & 0,333 & 0,416 & 5 \\
\hline
\end{tabular}

EK 5. Dematel Ağırlıklarına Göre Gri İlişki Dereceleri ve Sıralama

\begin{tabular}{|c|c|c|c|c|c|c|c|c|c|c|c|c|}
\hline Kriterler & $\mathbf{K}_{\mathbf{1}}$ & $\mathbf{K}_{\mathbf{2}}$ & $\mathbf{K}_{\mathbf{3}}$ & $\mathbf{K}_{\mathbf{4}}$ & $\mathbf{K}_{\mathbf{5}}$ & $\mathbf{K}_{\mathbf{6}}$ & $\mathbf{K}_{\mathbf{7}}$ & $\mathbf{K}_{\mathbf{8}}$ & $\mathbf{K}_{\mathbf{9}}$ & $\mathbf{K}_{\mathbf{1 0}}$ & $\boldsymbol{\Gamma}_{\mathbf{0 i}}$ & $\mathbf{S}_{\mathbf{1}} \mathbf{a} \mathbf{a m a}$ \\
\hline $\mathbf{A}_{\mathbf{1}}$ & 0,036 & 0,033 & 0,031 & 0,035 & 0,098 & 0,091 & 0,028 & 0,030 & 0,093 & 0,045 & 0,520 & \\
\hline $\mathbf{A}_{\mathbf{2}}$ & 0,109 & 0,033 & 0,049 & 0,035 & 0,098 & 0,046 & 0,085 & 0,090 & 0,093 & 0,045 & 0,683 & 2 \\
\hline $\mathbf{A}_{\mathbf{3}}$ & 0,055 & 0,099 & 0,049 & 0,035 & 0,033 & 0,030 & 0,085 & 0,030 & 0,093 & 0,134 & 0,643 & 3 \\
\hline $\mathbf{A}_{\mathbf{4}}$ & 0,109 & 0,099 & 0,097 & 0,104 & 0,033 & 0,030 & 0,028 & 0,030 & 0,093 & 0,134 & 0,757 & 1 \\
\hline $\mathbf{A}_{\mathbf{5}}$ & 0,036 & 0,033 & 0,031 & $0,0,35$ & 0,098 & 0,046 & 0,028 & 0,030 & 0,031 & 0,045 & 0,413 & 5 \\
\hline
\end{tabular}




\section{Measurement of Logistics Performance Elements in Travel Agencies with Integrated Dematel and GIA Methods and Selection of The Most Ideal Travel Agency: Case of Giresun Province}

\author{
Selçuk KORUCUK \\ Giresun University \\ School of Applied Sciences \\ Giresun, Turkey \\ orcid.org/0000-0003-2471-1950 \\ selcuk.korucuk@giresun.edu.tr
}

\author{
Eray TURPCU \\ Giresun University \\ School of Applied Sciences \\ Giresun, Turkey \\ orcid.org/0000-0002-6522-684X \\ eray.turpcu@giresun.edu.tr
}

\author{
Hakan AKYURT \\ Giresun University \\ School of Applied Sciences \\ Giresun, Turkey \\ orcid.org/0000-0002-6522-684X \\ hakan.akyurt@giresun.edu.tr
}

\section{Extensive Summary}

\section{Introduction}

As a result of the changes in tourism, it is seen that travel agencies have an important role when tourists are making holiday plans or entering into buying behavior. This is because; It is the role of travel agencies in helping to solve the most important issues for tourists such as trust, knowledge acquisition, time saving, credit facilities and reduction of costs.

Although the choice of travel agencies is an important concept, it is the fact that travel agencies are also an effective element of their own qualities. The services provided by travel agencies and the features of the agencies are effective in selecting agents for tourists.

In this study, it is aimed to determine the logistic performance elements of the travel agencies that carry out the logistics function in the tourism sector. By measuring the logistic performance of travel agencies and ranking the importance of performance factors, the criteria of the most ideal travel agency will be determined. In order to determine the performance of the travel agencies, GRA methods developed under the Multi System Critical Decision Making (MCDM) method and the Gray System Theory were used. In the results of the study, a multi-criteria decision model was set up to evaluate the criteria to be used in the logistic performance aspects of travel agencies in Giresun. Research on travel agencies in Giresun province revealed the status of the logistics performance of travel agencies. According to the data obtained, effective elements were determined in selecting the most appropriate travel agency and recommendations were made to provide better service in the sector of travel agencies operating in Giresun province.

In the literature review, it was not detected that the importance of the logistic performance factors and the selection of the most ideal travel agency were determined. 
This phenomenon is considered as a factor increasing the importance of the study. In addition, there is no study in which DEMATEL-GRA integrated approaches are used in choosing the most ideal travel agency with the logistic performance factors. Therefore, this study is expected to contribute to the literature.

\section{Method}

In order to determine the logistic performance elements of travel agencies in Giresun, Dematel, which is a Multi-Criteria Decision Making (MCDM) method, was used and the criterion weights were determined with Dematel. The most suitable travel agency has been selected by the GRA method.

\section{Dematel Method}

The DEMATEL method is the multi-criteria decision making approach introduced by the Geneva Battelle Memorial Institute (Wu et al., 2010, 5220). In order to determine the relationship between the elements of a mixed set of problems, Wu and Tsai (2011) expressed the method as studies to develop a structural model in order to prioritize the impact on each other within the context of these relationships. method.

Wu and Tsai (2011) and Erdal (2017) gave the following steps of the DEMATEL

\section{Step 1: Creating the Direct Relationship Matrix and Obtaining the Average Direct Relationship Matrix}

Direct relationship matrix; pairwise comparisons between the criteria are determined by the decision maker/expert group.

\section{Step 2: Creating Normalized Direct Relationship Matrix}

Using Equation (1) and (2), a normalized direct relationship matrix (C) is created. $a_{i j}$ elements are written instead of $x_{i j}$ elements. $(\mathrm{X})$ the sum of the rows and columns of the matrix is determined by the largest, and the average direct relationship matrix is divided into this value.

$$
\begin{array}{r}
s=\max \left(\max \sum_{j=1}^{n} x_{i j}, \max \sum_{i=1}^{n} x_{i j}\right) \\
C=\frac{X}{s}
\end{array}
$$

\section{Step 3: Create The Total Relationship Matrix}

Equations (3) and (4) are used to form the total relationship matrix (F). In these equations $I$ nxn size matrix, while decreasing indirect effects.

$$
\begin{gathered}
\lim _{k \rightarrow \infty} c+c^{2}+c^{3}+\ldots+c^{k} \\
F=C+C^{2}+C^{3}+\ldots+C^{k}=C(I-C)^{-1}
\end{gathered}
$$

Step 4: Determination of Affected and Affecting (Sender and Recipient) Criteria Groups 
In the previous step, based on the (F) matrix, the sum of the i'th row of this matrix $\left(D_{i}\right)$, represents the total of the effects (direct and indirect) that are sent to other criteria by the $\mathrm{i}$ criterion. The sum of columns $R_{i}$ refers to the sum of the effects from other criteria for the same criterion.

\section{Step 5: Calculation of Threshold Value and Drawing of Impact Diagram}

The direct determination of the threshold value by decision makers (or experts) is a classical and widespread approach.

\section{Step 6: Determination of Criterion Weights}

Priorities are determined using equations (5) and (6).

\section{GRA Method}

$$
\begin{gathered}
\mathrm{w}_{\mathrm{i}}=\sqrt{\left[\left(D_{i}+R_{i}\right)\right]^{2}+\left[\left(D_{i}-R_{i}\right)\right]^{2}} \\
\mathrm{~W}_{\mathrm{i}}=\frac{w_{i}}{\sum_{i=1}^{n} w_{i}}
\end{gathered}
$$

Developed under the Gray System Theory developed by Deng (1989), GRA is defined as a system that contains unknown information represented by gray numbers and gray variables (Chou and Tsai, 2009: 201).

The GRA implementation steps are given below (Zhai et al., 2009: 7074).

1. Determination of alternatives $(i=1, . ., m)$ and criteria $(j=1, . ., n)$.

$$
\chi_{\mathrm{i}}=\left(\chi_{\mathrm{i}}(1), \chi_{\mathrm{i}}(2), \chi_{\mathrm{i}}(3), \ldots \ldots \ldots, \chi_{\mathrm{i}}(\mathrm{n})\right)
$$

2. Creating Reference series based on the lowest (minimum) or maximum (maximum) values of comparable series

$$
\chi_{\mathrm{o}}=\left(\chi_{0}(1), \chi_{0}(2), \chi_{0}(3), \ldots \ldots ., \chi_{0}(\mathrm{n})\right)
$$

\section{Performing Normalization, Which Allows The Removal Of Values From The}

\section{Unit Effect.}

This process can be in three ways as described below:

Lower is better: : $\quad \chi_{\mathrm{i}}(\mathrm{k})=\frac{\max \chi_{\mathrm{i}}^{0}(\mathrm{k})-\chi_{\mathrm{i}}^{0}(\mathrm{k})}{\max \chi_{\mathrm{i}}^{0}(\mathrm{k})-\min \chi_{\mathrm{i}}^{0}(\mathrm{k})}$

Higher is better: : $\quad \chi_{\mathrm{i}}(\mathrm{k})=\frac{\chi_{\mathrm{i}}^{0}(\mathrm{k})-\min \chi_{\mathrm{i}}^{0}(\mathrm{k})}{\max \chi_{\mathrm{i}}^{0}(\mathrm{k})-\min \chi_{\mathrm{i}}^{0}(\mathrm{k})}$

The ideal value is better: : $\quad \chi_{\mathrm{i}}(\mathrm{k})=1-\frac{\left|\chi_{\mathrm{i}}^{0}(\mathrm{k})-\chi^{0}\right|}{\max \chi_{\mathrm{i}}^{0}(\mathrm{k})-\chi^{0}}$ 


\section{Calculation Of Grey Relational Coefficient Values As An Indicator Of Similarity Between Reference Series And Alternative Series}

$$
\varepsilon\left(\chi_{0}(\mathrm{k}), \chi_{\mathrm{i}}(\mathrm{k})\right)=\frac{\Delta_{\min }+\xi \Delta_{\max }}{\Delta_{\mathrm{oi}}(\mathrm{k})+\xi \Delta_{\max }}
$$

\section{Calculation Of Grey Relational Degree Values For Sorting Alternatives According To Similarity To Reference Series}

This calculation phase is calculated with the following equations depending on where the criteria are equal (13) and different (14):

$$
\begin{aligned}
& \gamma\left(\chi_{0}, \chi_{\mathrm{i}}\right)=\frac{1}{\mathrm{n}} \sum_{\mathrm{k}=1}^{\mathrm{n}} \varepsilon\left(\chi_{\mathrm{o}}(\mathrm{k}), \chi_{\mathrm{i}}(\mathrm{k})\right) \\
& \gamma\left(\chi_{0}, \chi_{\mathrm{i}}\right)=\sum_{\mathrm{k}=1}^{\mathrm{n}} \mathrm{w}_{\mathrm{i}}(\mathrm{k}) \varepsilon\left(\chi_{\mathrm{o}}(\mathrm{k}), \chi_{\mathrm{i}}(\mathrm{k})\right)
\end{aligned}
$$

\section{Implementation}

In this study, a multi-criteria decision model has been developed to evaluate the criteria to be used in the logistics performance elements of travel agencies operating in the province of Giresun. First of all, the criteria regarding the logistics performance elements in travel agencies have been determined by using expert opinion and literature survey. Since the specified criteria are not of equal importance, it is necessary to weigh the criteria.

\section{Weighting Criteria}

At this stage, which is used in the Dematel method, a decision matrix was created for the evaluation of the criteria. A total of 17 questionnaires were presented to academicians (4), business executives (9), Chamber of Commerce and Industry officials (4). According to dematel results, "travel service quality", "destination security" and "information and communication infrastructure" are the most important criteria for logistics performance. On the other hand, it was determined that the least important criteria were "Ease of Transportation", "travel time", "customs procedures", "Trade Infrastructure", "Travel demand and traceability", "Travel Delay Time" and "Transportation Costs and Safety" respectively.

\section{Sorting Alternatives}

The GRA technique was used to select the most ideal travel agency. The weight of the criteria obtained by the Dematel method was used to determine the travel agencies, in other words, the alternatives. According to GRA method, the selection of the ideal travel agency was the best alternative is "Company $\mathrm{D}$ " in the company rankings. On the other hand, for other companies, the ranking was $\mathrm{C}>\mathrm{B}>\mathrm{A}>\mathrm{E}$.

On the other hand, the most ideal company selection in travel agencies with the weights determined by the dematel method was also made in the ranking. According to the ranking the choice of the ideal travel agency according to the weights determined by 
Dematel in the company ranking, the best alternative "Company D" option was determined.

The "company D" option has been the best alternative in both the rankings mentioned above. In both applications, "Company A" and "Company E" are the other alternatives. The results of the two rankings were obtained by measuring the importance levels and the Dematel weight, which increased the reliability of the analyses.

\section{Conclusion and Recommendations}

In this study, logistic performance factors were prioritized by using DEMATEL and GRA methods, which MCDM methods, and the most suitable travel agency was selected by using the determined weights. In this evaluation, Logistics Performance elements were taken into account in total 10 criteria including "Travel Service quality", "Destination security", "Information and communication infrastructure", "Ease of Transportation", "travel time", "customs procedures", "trade infrastructure", "travel demand and traceability", " Travel Delay Time" and "transportation costs and security". Then, using the weights in the criteria, the ideal travel agency for the province of Giresun has been selected and ranked.

In the following stage, the most ideal travel agency was chosen by GRA method. According to the results of the GRA method, it was determined that the "Company D" alternative was the most ideal travel agency using the weights determined by the DEMATEL method.

When the relevant literature is reviewed, prioritization of the logistic performance factors in travel agencies by the Dematel method and the absence of any study related to the selection of the most suitable travel agency by the integrated Dematel-GRA methods are important factors in terms of contributing to the literature. In this regard, the study is an example of the evaluation / comparison of travel agencies from various angles. 